\title{
LETTERS
}

\section{NHS Health Check: national evaluation findings and implications}

Governments around the world are committing to primary prevention strategies to reduce the impact of cardiovascular disease on premature mortality, as recommended in evidence-based guidance, ${ }^{1-3}$ but there is uncertainty about the design and effectiveness of delivery programs.

Chang and colleagues ${ }^{4}$ report an evaluation of the National Health Service (NHS) Health Check program, adding to existing reports ${ }^{5,6}$ of low program coverage in the early years but broadly equitable take-up across socioeconomic and ethnic groups. The new data show a small absolute reduction in modelled 10-year cardiovascular risk from a health check (from $6.7 \%$ to $6.2 \%$ ), and that attendance was associated with significant decreases in blood pressure, body mass index and total cholesterol (but not in smoking). Prescribing of statins and antihypertensive medication increased but was still disappointingly low, even in high-risk patients.

The small size of the modelled reduction in risk remains a cause for concern, even if the study might have underestimated risk reduction due to missing or incomplete data and limited period of follow-up. The authors suggest the program falls short of "performance targets" but we would point out that uptake is now $49 \%{ }^{7}$ - more than double that reported in this study. The existing economic analysis did not show that $75 \%$ coverage was required to achieve cost-effectiveness as the authors imply.

Available evaluations show that vascular health check programs can identify large numbers of individuals at high risk. The challenge is to ensure that those patients receive effective and coordinated follow-up care to reduce that risk.

We agree that it is essential to continue to evaluate overall impact using more recent and complete data. Research is also needed on implementation to establish best practice and further improve program performance.

\section{John N. Newton}

Chief Knowledge Officer, Public Health

England, London, UK

\section{Katherine Thompson}

Deputy National Lead, NHS Health Check and Blood Pressure Programme, Public Health England; on behalf of the NHS Health Check Expert Scientific and Clinical Advisory Panel
Cite as: CMAJ 2017 January 30;189:E172. doi: $10.1503 / \mathrm{cmaj} .732012$

\section{References}

1. Cardiovascular disease prevention public health guideline. London (UK): National Institute for Health and Care Excellence; 2010. Available: www.nice.org. uk/guidance/ph25/resources/cardiovascular-disease -prevention-1996238687173 (accessed 2016 May 20).

2. Cardiovascular disease: risk assessment and reduction, including lipid modification. London (UK): National Institute for Health and Care Excellence; 2015. Available: www.nice.org.uk/ guidance/cg181/resources/cardiovascular-disease -risk-assessment-and-reduction-including-lipid -modification-35109807660997 (accessed 2016 May 20).

3. Package of essential non-communicable (PEN) disease interventions for primary health care in low-resource settings. Geneva: World Health Organization; 2010. Available: www.who.int/ $\mathrm{nmh}$ /publications/essential_ncd interventions_lr _settings.pdf (accessed 2016 May 20).

4. Chang KC, Lee JT, Vamos EP, et al. Impact of the National Health Service Health Check on cardiovascular disease risk: a difference-in-differences matching analysis. CMAJ 2016;188:E228-38.

5. Chang KC, Soljak M, Lee JT, et al. Coverage of a national cardiovascular risk assessment and management programme (NHS Health Check): retrospective database study. Prev Med 2015;78:1-8.

6. Robson J, Dostel I, Sheikh A, et al. The NHS Health Check in England: an evaluation of the first 4 years. BMJ Open 2016;6:e008840.

7. Public health outcomes framework: NHS Health Check profile. London (UK): Public Health England. Available: www.phoutcomes.info/ (accessed 2016 May 20). 